\title{
Commentary: Lungs across borders: American lungs in Canadian patients
}

Michael E. Bowdish, MD, MS, ${ }^{\mathrm{a}, \mathrm{b}}$ and

Mark L. Barr, MD ${ }^{\mathrm{a}}$

The optimal system for equitable and just donor lung allocation remains debatable. Canada and the United States share a common border and similar levels of advanced health care. In addition, US and Canadian physicians have a long history of collaboration in the field of transplantation, with many cross-national-trained physicians heading some of the best thoracic transplant programs in the world.

However, organ-allocation systems in both countries differ, and each prioritizes the direction of donor organs to residents of the respective country before potential donation across the border, regardless of distance or other known risk factors for decreasing wait list mortality and optimizing outcomes. In the United States, the policies of the national regulatory body overseeing organ donation, the Organ Procurement Transplantation Network, allow for the exportation of donor organs to nondomestic medical centers only after offering these organs to all potential US transplant recipients on the organ match run. Canada likewise allows exportation of organs to US recipients under similar circumstances.

In the current issue of the Journal, Cypel and colleagues ${ }^{1}$ from the University of Toronto present a comparison of lung transplant outcomes in patients at their center who received lungs recovered in the United States. The presumption is that these donor lungs would be of poorer quality and

\footnotetext{
From the Departments of ${ }^{\mathrm{a}}$ Surgery and ${ }^{\mathrm{b}}$ Population and Public Health Sciences, Keck School of Medicine of USC, University of Southern California, Los Angeles, Calif. Disclosures: The authors reported no conflicts of interest.

The Journal policy requires editors and reviewers to disclose conflicts of interest and to decline handling or reviewing manuscripts for which they may have a conflict of interest. The editors and reviewers of this article have no conflicts of interest.

Received for publication Dec 1, 2021; revisions received Dec 1, 2021; accepted for publication Dec 2, 2021; available ahead of print Dec 6, 2021.

Address for reprints: Michael E. Bowdish, MD, MS, Keck School of Medicine of USC, University of Southern California, 1520 San Pablo St, HC2 Suite 4300,

Los Angeles, CA 90033 (E-mail: Michael.Bowdish@med.usc.edu).

J Thorac Cardiovasc Surg 2022;164:1669-70

$0022-5223 / \$ 36.00$

Copyright (c) 2021 by The American Association for Thoracic Surgery

https://doi.org/10.1016/j.jtcvs.2021.12.004
}

The message is clear. Lungs deemed marginal in the United States can be used at a premier lung transplantation center, such as the University of Toronto, with excellent results. The corollary is of course that US centers may be passing over reasonable organs for patients on their waiting lists. Admittedly, a center such as Toronto is one of the most experienced in the world and aggressive with the use of EVLP, hepatitis C virus-positive donors, and donation after cardiac death donors and is willing to travel longer distances than many US centers. That said, US centers can likely learn from this experience. While unlikely to occur,

therefore perhaps associated with worse outcomes. The results are quite the opposite, with equivalent outcomes between groups. Of note, the incidence of US donors increased from 5\% to $15 \%$ from 2009 to 2018 , and US donors were more likely to be hepatitis $\mathrm{C}$ virus positive and to be placed on ex vivo lung perfusion (EVLP). Of potentially greatest interest in what is now a postregulatory approval era for this technology in the United States, 58 of the US lung cohort were transplanted following EVLP (46\% of the cases) with a use rate after EVLP of $56 \%$, with the caveat that EVLP was only used for standard criteria lungs. Cold ischemic times and preservation times were, not surprisingly, longer by about 1 hour in the US donors. However, nearly one half $(60 / 124,48 \%)$ of the US lungs came from organ procurement organizations within 500 miles of Toronto (specifically Michigan, Illinois, and Pennsylvania). Despite these differences, the majority of outcome metrics were nearly identical. 
it may also be worth reconsidering national borders in organ allocation-as using lungs across borders may be beneficial to the transplant community as a whole.

\section{Reference}

1. Cypel M, Yeung J, Donahoe L, Yasufuku K, Pietroski R, Lange P, et al. Outcomes of lung transplantation at a Canadian center using donors declined in the United States. J Thorac Cardiovasc Surg. 2022;164:1661-8.e1.
See Article page 1661.

\section{Commentary: A sobering reality: Donor lungs declined in the United States transplanted successfully in Canada}

\author{
Christian A. Bermudez, MD, and \\ Maria M. Crespo, MD $^{b}$
}

Cypel and colleagues ${ }^{1}$ present their experience with lung transplantation using donor lungs that were declined by centers in the United States and then offered to their center in Ontario, Canada. Over a 10-year period (from 2009 to 2019), 124 patients underwent lung transplantation using these organs. During the same period, they performed 1300 transplants using lungs from direct offers from Canadian centers. The percentage of transplanted patients with lungs from an American donor increased from 5\% to $15 \%$ over this time. Their results are very compelling, showing similar short-and long-term outcomes, similar incidence of primary graft dysfunction and chronic lung allograft dysfunction, and similar need for extracorporeal membrane oxygenation after lung transplantation when comparing recipients of lungs from a Canadian center with recipients of lungs from an American center.

In their study, donors from the United States were younger and more commonly hepatitis $\mathrm{C}$ virus-positive by nucleic acid testing than Canadian donors. Ex vivo lung

From the Divisions of ${ }^{\mathrm{a}}$ Cardiovascular Surgery and ${ }^{\mathrm{b}}$ Pulmonary, Allergy, and Critical Care, University of Pennsylvania Health System, Philadelphia, Pa.

Disclosures: Dr Bermudez is member of the medical advisory board for Abbott and Breethe (Abiomed). Dr Crespo reported no conflicts of interest.

The Journal policy requires editors and reviewers to disclose conflicts of interest and to decline handling or reviewing manuscripts for which they may have a conflict of interest. The editors and reviewers of this article have no conflicts of interest.

Received for publication Dec 9, 2021; revisions received Dec 9, 2021; accepted for publication Dec 15, 2021; available ahead of print Dec 18, 2021.

Address for reprints: Christian A. Bermudez, MD, Division of Cardiovascular Surgery, University of Pennsylvania Health System, 3400 Spruce St, Philadelphia, PA 19104 (E-mail: Christian.Bermudez@pennmedicine.upenn.edu).

J Thorac Cardiovasc Surg 2022;164:1670-1

0022-5223/\$36.00

Copyright $₫ 2021$ Published by Elsevier Inc. on behalf of The American Association for Thoracic Surgery

https://doi.org/10.1016/j.jtcvs.2021.12.023

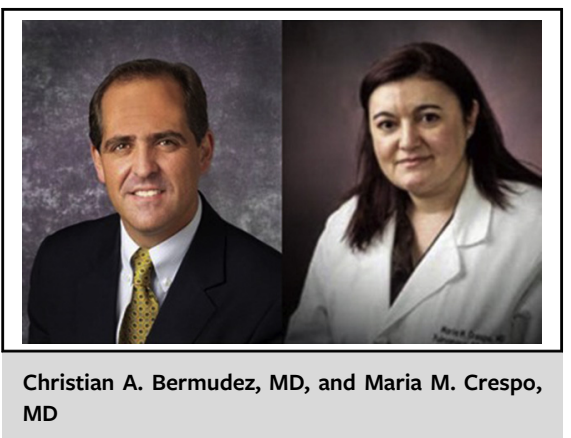

CENTRAL MESSAGE

Lungs declined in the United States were transplanted in Canada with acceptable outcomes. We need to better understand the reasons for declining lungs to increase the organ pool in the United States.

perfusion (EVLP) was used more frequently in lungs from American donors ( $46 \%$ vs $27 \%$ ), despite similar lung function among the American donors and Canadian donors at the time of procurement. This is not surprising given the extensive center experience of the Toronto group with EVLP. The reasons for higher use of EVLP in lungs from American donors are not specified, but this study also suggests that EVLP and reconditioning may ameliorate lung injury in some cases and allow transplantation from donors previously deemed unsuitable, as previously published by the authors. ${ }^{2,3}$ Despite the frequent use of EVLP, it is also notable that $54 \%$ of the lungs from donors in the United States were transplanted directly, with overall preservation times $>10$ hours. This highlights that adequately recovered and preserved donated lungs can tolerate long ischemic times without adverse outcomes.

According to the Organ Procurement and Transplantation Network/Scientific Registry of Transplant Recipients 2019 Annual Data Report, the number of lung transplants performed continues to increase annually and 